\title{
THE ACCURACY ANALYSIS OF LIDAR-DERIVED ELEVATION DATA FOR THE GEOMETRIC DESCRIPTION OF CROSS-SECTIONS OF A RIVERBED
}

\author{
G. Caroti $^{\text {a, } *, \text { F. Camiciottoli }^{\text {b }}, \text { A. Piemonte }}{ }^{\text {a }}$, M. Redini ${ }^{\text {c }}$ \\ ${ }^{\text {a }}$ Laboratorio A.S.T.R.O., Dipartimento di Ingegneria Civile e Industriale,Università di Pisa, Largo Lucio Lazzarino 1 \\ 56123 PISA, tel 050221 7770, fax 050221 7779, e-mail gabriella.caroti@ dic.unipi.it \\ ${ }^{\mathrm{b}}$ Provincia di Arezzo, Servizio Difesa del Suolo, Via Arrigo Testa 2, \\ 52100 AREZZO, tel 0575 316210, fax 0575 316241, e-mail fcamiciottoli@provincia.arezzo.it \\ ${ }^{\mathrm{c}}$ Comune di Pisa, m.redini@comune.pisa.it
}

KEY WORDS: DEM/DTM, LIDAR, Floods, Hydrology, Hazards

\begin{abstract}
:
The work stems from a joint study between the Laboratory ASTRO (Department of Civil and Industrial Engineering - University of Pisa), the municipality of Pisa and the province of Arezzo on the advanced analysis and use of digital elevation data. Besides, it is framed in the research carried on by ASTRO about the definition of the priority informative layers for emergency management in the territory, as of PRIN 2008. Specifically, this work is in continuity with other already published results concerning rigorous accuracy checks of LIDAR data and testing of the procedures to transform raw data in formats consistent with CTR and survey data. The analysis of sections of riverbed, derived from interpolation by DTMs featuring different grid density with those detected topographically, is presented. Validation by differential GNSS methodology of the DTMs used showed a good overall quality of the model for open, low-sloping areas. Analysis of the sections, however, has shown that the representation of small or high-sloping (ditches, embankments) morphological elements requires a high point density such as in laser scanner surveys, and a small mesh size of the grid. In addition, the correct representation of riverside structures is often hindered by the presence of thick vegetation and poor raw LIDAR data filtering.
\end{abstract}

\section{INTRODUCTION}

The work stems from a joint study, between the ASTRO Laboratory of the Department of Civil and Industrial Engineering - University of Pisa, the municipality of Pisa and the province of Arezzo, about analysis and advanced use of digital elevation data, and is included in the research that the Laboratory ASTRO is carrying on about the definition of the primary informative layers for emergency management in the territory, as defined by PRIN 2008 project.

The work aims to conduct an analysis of accuracy and quality of topographic databases used as support in hydraulic tests for risk definition and management and subsequent land management. In detail, a description is provided for some methods by which digital elevation models (DEMs) can be derived, i.e. interpolation from existing maps or dedicated Lidar measurements. The precision with which land elevation can be defined is subsequently analyzed.

Methods of defining riverbed geometry are then analyzed along with their possible extrapolation by interpolation from existing high-density digital elevation models.

Finally, some insights are provided on the integration between the different topographical databases and the implications that these additions may have on aspects of planning, that also play some important economic interests.

\section{TOPOGRAPHIC DATA PRECISION}

\subsection{Digital Elevation Models}

For the definition of areas of danger outside the riverbed, a 3-D rendering of the area around the riverbed itself is required. This rendering is provided by digital elevation models (DTMs) and is used to outline areas of flooding and to define the motion of the flood waves outside the riverbed.
For these purposes, FEMA (Federal Emergency Management Agency) recommends using a high-density, high-precision model. In Italy, thanks to the Lidar-based national remote sensing plan for the updating of the database of the National Cartographic Portal (NCP) digital elevation models of some river courses, all shorelines and areas of high hydrogeological criticality have been produced. These models can be considered compliant with the requirements of FEMA.

DTM accuracy is highly important especially with the latest advances in technologies for high-resolution earth surface modelling, for example with laser scanning (Pirotti et al., 2013a). In some of our previous published works, analysis of the quality and accuracy of these DTMs have been carried out assessing accuracies of the order of a few inches in elevation representation of the territory for the high-density DTM analyzed (Caroti et al., 2011). In particular, validation of the test area used for checking in the present work, the shaft of Sovara Creek, a right-hand tributary of the Tiber River, involved a hundred points distributed in the area with particular attention in order to homogenize the GNSS validation surveys with DTM regarding the framing in planimetric and altimetric data and therefore exclude in advance some possible systematic errors (Figure 1).

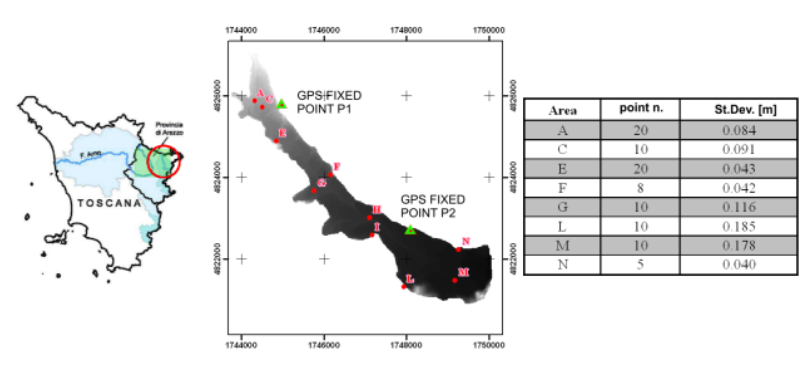

Figure 1. Check points position in the test area 
Until the adoption of Lidar technique, however, rendering of the horizontal and vertical appearance of the territory was almost exclusively obtained by interpolating the information contained in the Regional Technical Map (CTR), on 1:10000 or 1:2000 scales.

Although Lidar measurements are available for many parts of the Italian territory, map-derived models are still used where data is missing, also because land management procedures are often based on these maps. For example, in the Tuscany Region, levels of local planning, i.e. Structural Plans and Urban Planning Regulations, are produced on 1:10000 and 1:2000 CTRs, respectively (1.r. $\mathrm{n}^{\circ}$ 01/2005 and subsequent mods.).

The accuracy level of the models obtained from altimetric information contained in the maps obviously depends on their scale factor. Accuracy of the spot elevations in the Tuscany Region CTR maps has been checked for assessment. In particular, starting from the planimetric coordinates of the spot elevations, their orthometric height was obtained by bilinear interpolation from the DTM. This height was then compared with that of cartography.

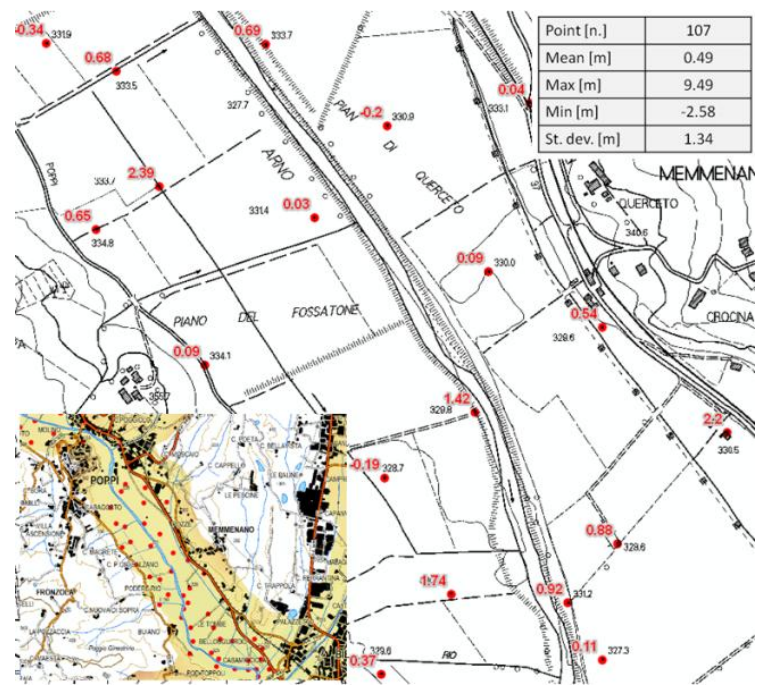

Figure 2. CTR 1:10000 and DTM interpolated height comparison

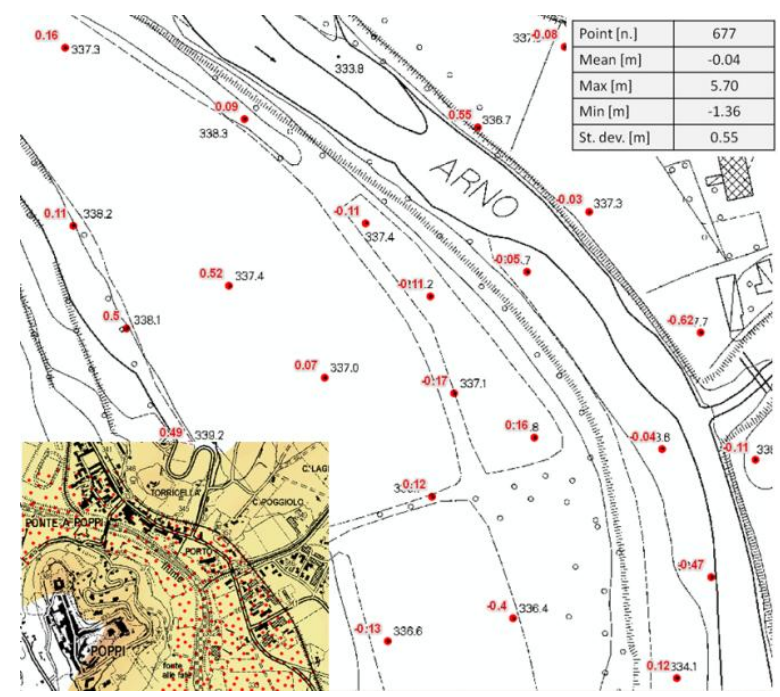

Figure 3. CTR 1:2000 and DTM interpolated height comparison
The results, shown in Figures 2 and 3, show a standard deviation of $1.34 \mathrm{~m}$ for the $1: 10000 \mathrm{CTR}$ and $0.55 \mathrm{~m}$ for the 1:2000 CTR. Besides, it must be noted that these spot elevations have a mutual distance of approximately $200 \mathrm{~m}$ in 1:10000 CTR (about 0.5 points/ha) and $50 \mathrm{~m}$ in 1:2000 CTR (about 2 points/ha). These distances obviously limit the possibility to interpolate a DTM that could represent the highfrequency variations of territory course.

\subsection{Scale of representation}

A final comment should be made on issues related to the use of information layers in maps of different scale than those on which they were generated. The example of Figures 4 and 5 reports a case of outlining of the Excerpt Plan on Hydraulic Risk Reduction for the Basin of the River Arno. The outline has been based on 1:25000 Italian Military Geographical Institute maps and is the graphic documentation accompanying official rules on land management. If the same outline, whose cartographic coordinates digitized on old 1:25000 maps are known, is superimposed to cartography at a larger scale (figure 6 shows the example with a 1:10000CTR) or to new 1:25000 maps (Figure 5), its inconsistency with the actual position of the boundaries to which it was originally meant to refer, such as the side of the road on the north side, is obvious at a first glance.

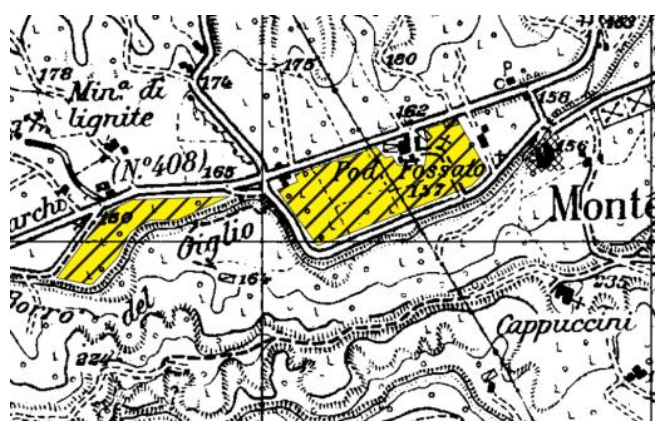

Figure 4. A case of outlining in IGM Map 1:25000 of the Excerpt Plan on Hydraulic Risk Reduction for the Basin of the

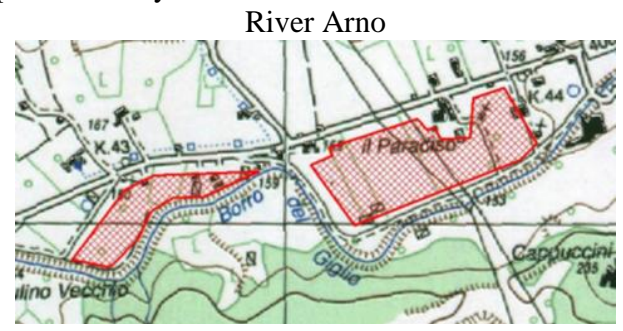

Figure 5. The same shape file superimposed to new IGM Map 1:25000 derived from CTR 1:10000

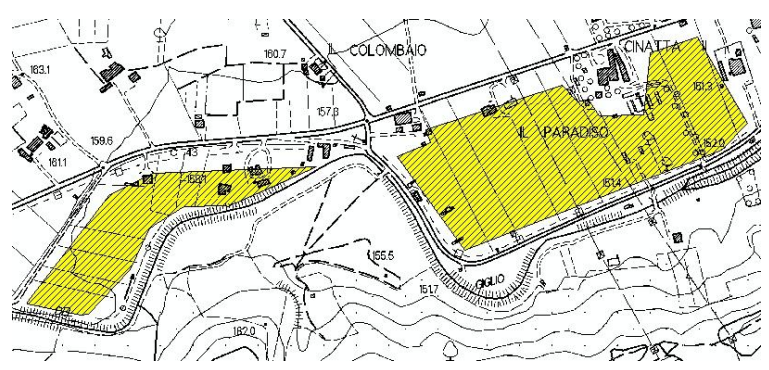

Figure 6 . The same shape file superimposed to cartography at a larger scale (CTR 1:10000) 
These considerations highlight the possible problems arising from the use of multi-scale spatial information and emphasize the need for strict standardization, on the part of land management authorities, of procedures for the integration of such information. These procedures are sometimes required to provide for a review of the data according to scale of use and cartographic base.

\section{RIVERBED GEOMETRY CHECK}

Hydraulic modelling of the riverbed inside is performed through specific software tools requiring the input of riverbed geometries as defined through cross sections, usually obtained with centimetric accuracies by topographical methods (total station, GNSS) every few hundred meters.

It has previously been pointed out that in Italy the availability of high-density digital elevation models for river courses, especially for those with high hydraulic risk, is ever increasing.

Therefore, the evaluation of feasibility of extrapolating cross sections by interpolation from the DTM and achievable accuracy has been targeted, interpolating sections to match those surveyed in the field and comparing the courses.

The available DTM has a $2 \mathrm{~m}$ square grid, derived from a $2 \div 3$ points $/ \mathrm{m}^{2}$ Lidar survey (2007) with a Toposys 2 sensor and maximum flying height of $1500 \mathrm{~m}$, which provided $\pm 30 \mathrm{~cm}$ height accuracy as per specifications. It must also be noted that the survey was carried out during the minimum flow and the comparison of the sections has been restricted to the dry areas.

The topographic field survey was carried out using Stop \& Go RTK GPS methodology with a local master, framed in turn in ETRF89 via the Arezzo GPS permanent station. It should be emphasized that the abovementioned Lidar survey used the same permanent station for the framing of digital models output. Furthermore, for both databases the same IGM grids have been used for coordinate transformation, both planimetric, from UTM-ETRS89 to Gauss Boaga, and altimetric, from ellipsoidic to orthometric height.

The topographic survey has been extended to about $60 \mathrm{~m}$ over the banks of the ordinary riverbed and any embankment, detecting one point every roughly $20 \mathrm{~m}$, except for specific cases of morphological variation of the ground.

The representation of the river banks and riverbed floor has taken place through a number of points strictly required to characterize the shape of the section; in particular the riverbed was represented through the detection of at least five points, including intersections with the water level. The embankments, where present, were represented through the acquisition of at least four points, and the ditches on the outer edge, if any, were also detected. The shores and cliffs of the riverbed and the embankments were discretized in order to highlight the significant points of slope change.

In the first place, a visual comparison between the measured sections and those obtained by interpolation of the DTM was carried out.

The most significant differences were found in the area between the foot of the outer slopes of the river banks (Figure 7); outside the riverbank limits, where in almost all cases there are crops or other flat areas, matching is very good (Figure 8). This feature is recurrent in all 27 sections analyzed, which are distributed along the course of the river for about $15 \mathrm{~km}$.

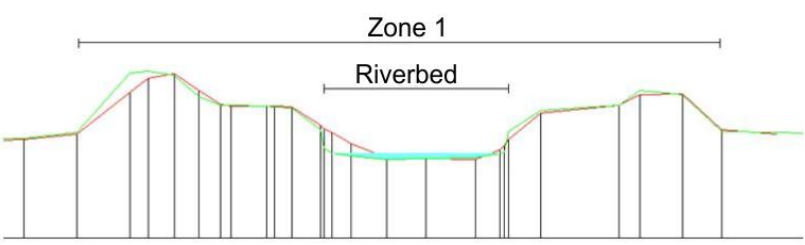

Figure 7. Zone 1: area between the foot of the embankment slopes. Topographic survey in green and interpolated surface from DTM in red

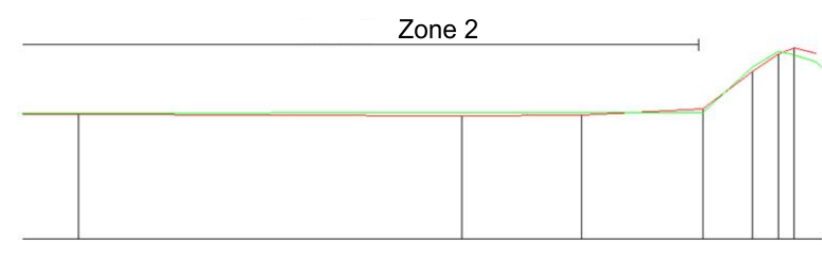

Figure 8. Zone 2: area outside the banks of the river. Land topographically surveyed in green and interpolated surface from DTM in red

Such observations are also quite obvious in the planimetric representation of Figure 9, and point out a lower degree of reliability of elevation models to describe riverside areas in general.

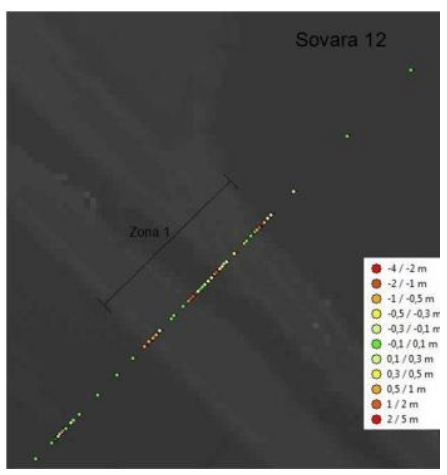

Figure 9. Distribution of the discrepancies between measured and interpolated height along the section surveyed

The most critical cases were therefore analyzed.

In particular, in some of these cases the magnitude of the filtering function on the raw data, due to the availability of data of the first and last laser pulse, has been highlighted.

As a typical case study, the DTM overestimates land elevation. There are in fact many areas where the course reconstructed by DTM interpolated elevation is higher than the actual one.

This can be found primarily in areas with a high tree density, especially of shrub-type (Figures 10 and 11). The presence of vegetation and its incorrect filtering can lead to the aforementioned problems of overestimation. 


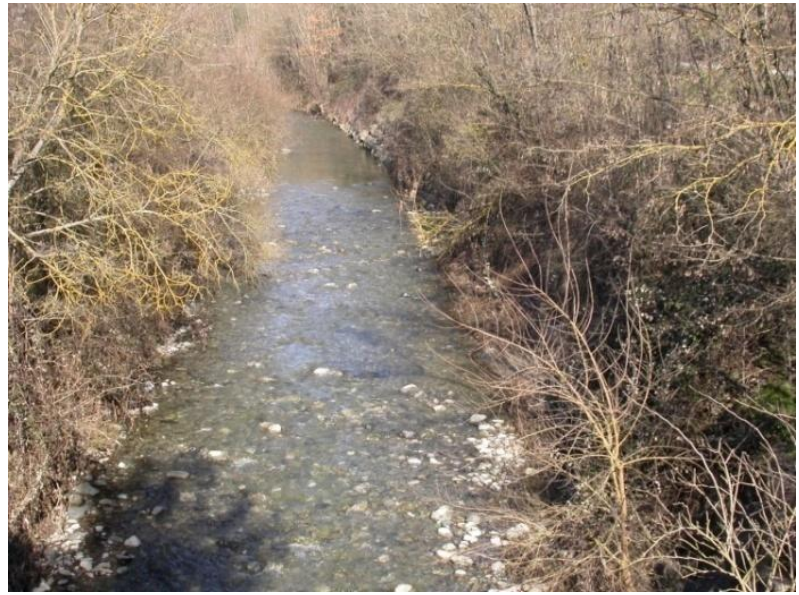

Figure 10. Example of area for which DTMs overestimate land elevation

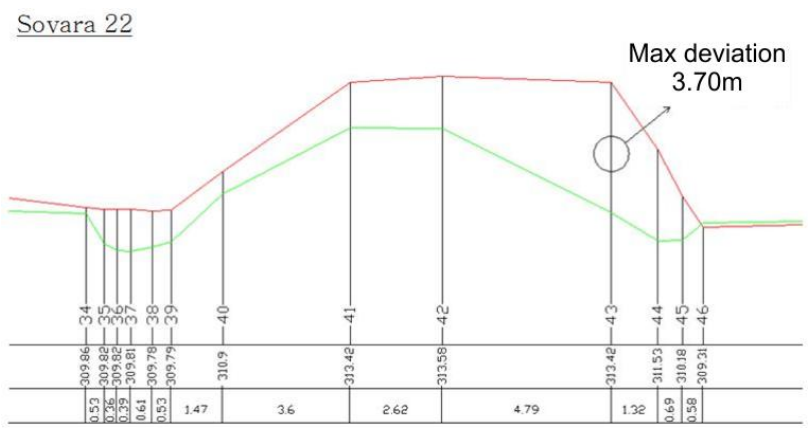

Figure 11. Example of area for which DTMs overestimate elevation. Topographic survey in green, DTM interpolated surface in red

Interpolating a new profile of the same section of the DSM (Figure 12) shows high deviations with respect to topographically measured land elevation. This result is not unusual given the presence of vegetation. First pulse DSM, in fact, gives a survey of the ground or anything that rises above the surface, including buildings, trees and vegetation in general. Interpolating the section outline of last pulse DSM yields a trend very similar to the previous one (Figure 13). This result is partially unexpected, because the last pulse should produce a more faithful representation of the land course. Obviously, in case of very thick vegetation, the availability of different laser returns doesn't help much for a proper filtering of the DTM.

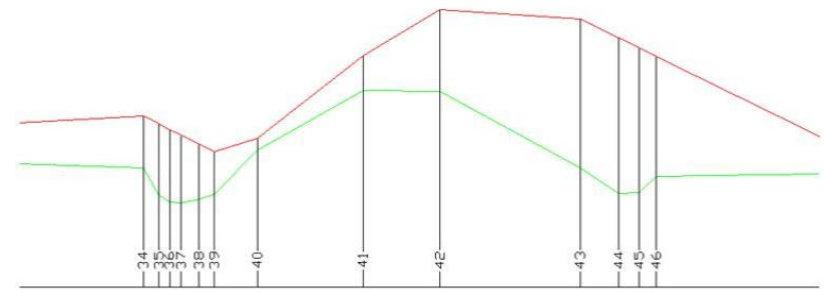

Figure 12. Example of area for which DTMs overestimate elevation. Topographic survey in green, first pulse DSM interpolation in red

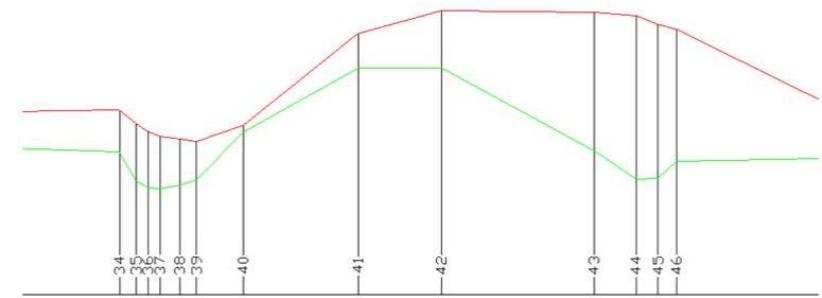

Figure 13. Example of area for which DTMs overestimate elevation. Topographic survey in green, last pulse DSM interpolation in red.

Another case study occurs when the DTM must describe small morphological elements with peculiar geometries. In particular, the rendering of drainage ditches has been studied. These ditches (Figure 14) run externally along the banks of the Sovara in almost all sections in order to channel rainwater from the surrounding areas within the riverbed of the creek. Although the differences are not relevant (tolerance is always met), it is interesting to note this limit of DTM in describing continuums on the territory.

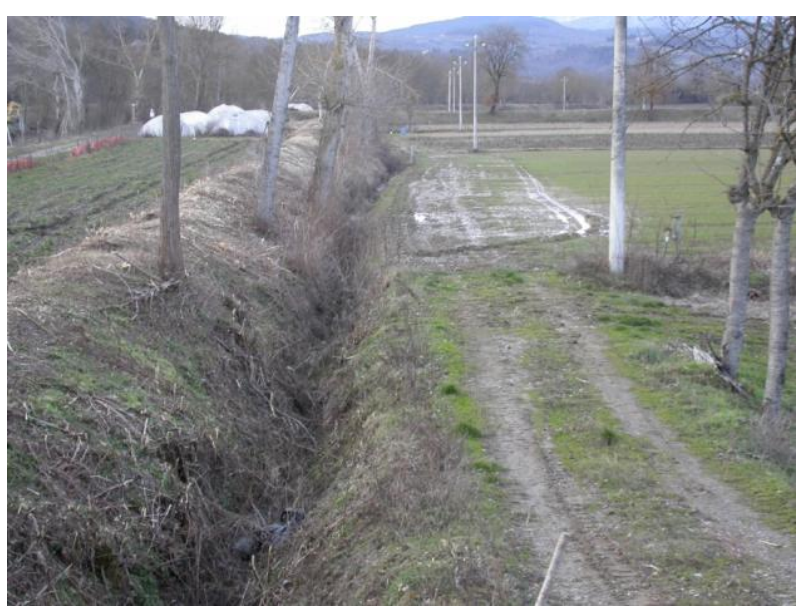

Figure 14. Example of drainage ditch

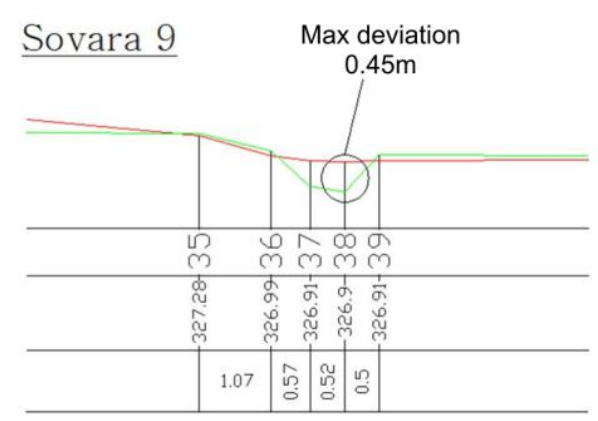

Figure 15. Example of drainage ditch not represented in the DTM - Topographic survey in green, last pulse DSM interpolated surface in red

This issue is related to the number of points surveyed per square meter. The sampling rate determines the planimetric size of detectable ground irregularities. It is not, therefore, a processing or surveying error, but rather a limit inherently linked to point density as required in contract specifications. 
It must, then, be pointed out that important features in hydraulic design, such as drainage ditches, cannot be properly represented by DTMs (Figure 15).

A final aspect that arose from this study is the difficulty that sometimes has the DTM in successfully reconstructing embankment geometry. The most frequent anomalies relate to high slope areas and points with sudden changes in ground slope.

Figures 16 and 17 show the case in which the problem of representation relates to an artificial embankment that determines an abrupt variation in the ground height. By analogy with drainage ditches, DTM surfaces are likely to be affected by the undersampling of such structures.

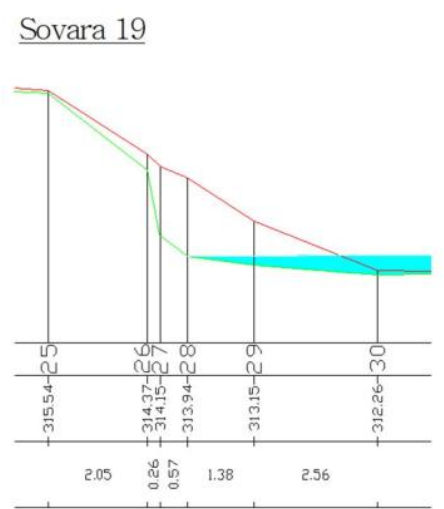

Figure 16. Example of artificial embankment slope - Land topographically detected in green and interpolated surface from DTM in red

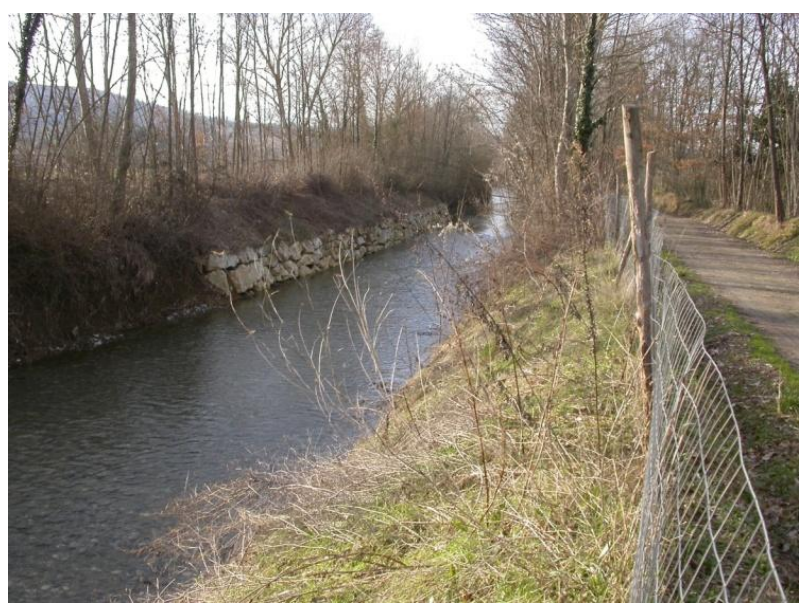

Figure 17. Artificial embankment

A final analysis was conducted on the ability of the DTM to provide elevation information of embankment summits (figure 18). In every section the deviations between elevations interpolated from digital models and those measured topographically are within tolerance. In the case of vegetationfree embankments, however, the tendency of the digital model to underestimate, even if only slightly, the actual trend of the soil should be emphasized.

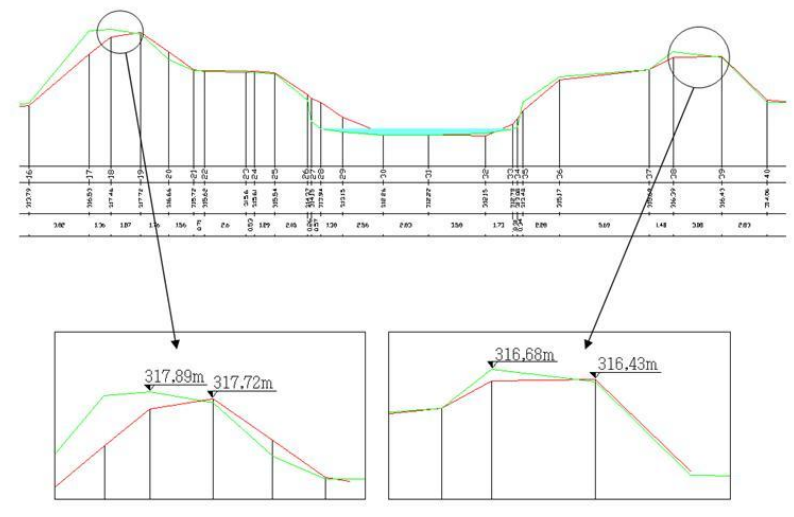

Figure 18. Determination of elevation of embankment summit Topographic survey in green, interpolated surface from DTM in red

\section{INTEGRATION BETWEEN DATABASES}

During the work described in the previous section, the two databases compared are not affected by integration problems caused by systematic errors due to the use of different reference frames. As already mentioned, in fact, they have been georeferenced using the same procedures and the same parameters of coordinate transformations. The differences between topographically detected and interpolated riverbed geometries are then entirely due to the methodology of survey and processing of the relevant Lidar data. It should be noted, moreover, that the same attention was paid during the validation of the DTM, which allowed for the attainment of the good results reported in the second section.

This ideal situation, however, is not common. Very often, there is a need to integrate across topographic databases compiled at different times, at different scales and often referred to different systems. In addition, operators often fail to accompany the data collected with the appropriate metadata that enables their proper use.

A specific example related to the findings discussed in this work is the integration between topographic surveys, which allow inriverbed modelling, with digital elevation models, which allow modelling on the outside of the riverbed.

If the framing of riverbed geometry and of the DTM are not homogeneous, major systematic errors may occur, resulting in discontinuities in the transition between riverbed, embankments and surrounding land.

Table 1 below shows the approximate theoretical values of some systematic errors due to hypothetical heterogeneities in elevation framing.

\begin{tabular}{|l|c|}
\hline \multicolumn{1}{|c|}{ Framing elevation anomaly } & difference [m] \\
\hline $\begin{array}{l}\text { GPS surveys analyzed in ETRF89 or in } \\
\text { ETRF2000 datum }\end{array}$ & $\pm 0.07 \div \pm 0.10$ \\
\hline $\begin{array}{l}\text { Ellipsoidal elevations converted into } \\
\text { orthometric by Italgeo99 or Italgeo2005 }\end{array}$ & \pm 0.12 \\
\hline
\end{tabular}

Table 1. Theoretical values of systematic errors

With the increasing diffusion of GPS permanent stations networks, surveys are more homogeneous than in the past. Previously, in fact, GPS surveys were carried out by measuring local area networks, each of which standing alone with regard to 
framework, measure compensation and seven parameters coordinate transformation used.

\section{CONCLUSIONS}

The present work suggests some conclusions. Firstly, it confirms the good overall accuracy of digital elevation models obtained from Lidar measurements. Such precision, despite the availability of small-meshed $(1 \div 2$ meters) grids, is reduced in areas with sudden slope changes. Moreover, the results are not always optimal in the presence of thick vegetation. Both problems are common in the study of riverside areas

Nevertheless the sections obtained by interpolation from DTM have often proved of good quality, differing from those detected topographically only in some cases.

It would be advisable to complement this study, purely topographical and geometric, with an analysis of the changes involved in the hydraulic modeling geometric representation by the differences between the two methods of survey of riverbed sections.

In any case, it seems unlikely that DTM derived sections will replace those detected topographically, which, thanks to a definitely higher precision degree, constitute an essential tool to achieve a correct modeling of riverbeds. On the other hand, they may serve, on the inner side of riverbeds, to integrate the latter with information on the features of riverbed included between one section and the other, but above all for a more detailed description of the surrounding ground and, therefore, for better modeling of the behavior of out-bed floods. Furthermore, in some cases, such as emergency situations or lack of economic resources to carry out dedicated surveys, it may be required to define these geometries in a more expeditious way, in which cases dense elevation models could be used.

It is also noted that, in spots with thick vegetation, the algorithm for the production of the DTM is not always able to operate the filtering of DSM data so as to allow the reconstruction of the correct geometry of the ground, given that elevation values of both DTMs and DSMs are substantially homogeneous (Pirotti et al., 2013b). As already mentioned, then, there can be no certainty as to get fair accuracy levels from the DTM and it is not advisable to rely solely on digital elevation models to characterize the geometry of riverbeds and embankments.

More generally, it seems worthwhile to draw attention to the importance, for public offices, to have precise information on the timing and method of collecting data for the performance of ordinary topographic surveys, in order to simplify survey and / or test phases, minimizing time and cost of execution.

Finally, stress must be placed on the importance of accompanying the surveys with all the metadata required for the proper integration of the datum in which the surveys have been framed.

It seems desirable to encourage the integration of information from different sources and, especially with regard to high-detail topographic surveys, to lay down the procedures for methods of both production (field surveys, post-processing and rendering) and storage and management of data, in order to increase the usability of the information produced by the authorities in charge of land management in the conduct of its institutional activities.

\section{REFERENCES}

Bertagni, G., Cuscini, N., Sadun, S., 2006. Campagna di rilevo LIDAR sul territorio del bacino del Fiume Serchio. Cartographica (17), pp. 8-12.

Berti, C., et al., 2008. La precisione dei rilievi effettuati con GPS differenziale statico e RTK: il caso della Provincia di Arezzo, In: Proceedings 12a Conferenza Nazionale ASITA.

Berti, C., et al., 2008. Valutazione degli errori sistematici nella produzione di DTM con tecnologia LIDAR aviotrasportata, Proceedings 12a Conferenza Nazionale ASITA.

Berti, C., et al., 2007. Modelli digitali da laser-scanning per la ricostruzione di sezioni fluviali. Strategie di valutazione delle precisioni, Proceedings Convegno Nazionale SIFET, Arezzo.

Berti, C., Camiciottoli, F., Casiglia, A., Redini, M., Surace, L., 2006. Confronto tra rilievo topografico integrato con misure GPS e dati Laser-scanning da aereo, Atti della 10a Conferenza Nazionale ASITA.

Brovelli, M.A., Caldera, S., Liu, X., Sansò, F., 2009. Valutazione dell'accuratezza tridimensionale di un modello digitale del terreno, Proceedings Convegno Nazionale SIFET, Mantova, pp. 31-36.

Brovelli, M.A., Cilloccu, F., Dequal, S., Crespi, M., Lingua, A., 2009a. Linee guida Ortoimmagini 1:10.000 e modelli altimetrici, Collana di documenti CISIS.

Camiciottoli, F., Radicchi, L., 2005. Disciplinare tecnico. Campagna di rilevamento topografico plano altimetrico, Provincia di Arezzo. Servizio Difesa del Suolo, Arezzo.

Camiciottoli, F., Redini, M., Surace, L., 2005. Tecnologia laser-scanning e rischio idraulico, ISBN 88-7781-689-9, Provincia di Arezzo - Difesa del suolo.

Caroti G., Piemonte A., 2011. Analisi dei dati altimetrici disponibili per il territorio comunale di Pisa, Geomatica le radici del futuro, pp.157-161, Edizioni SIFET

Casella, V., Spalla, A., Zamponi, B., 2001. Estrazione del DTM di precisione dell'argine di un fiume: fotogrammetria analitica, fotogrammetria digitale e laser scanning a confronto. Bollettino SIFET II/2001, pp.193-211.

Ministero dell'Ambiente e della Tutela del Territorio e del Mare, Direzione Generale della Difesa del Suolo, 2007. Piano straordinario di telerilevamento ambientale ad alta precisione per le aree ad alto rischio idrogeologico: Disciplinare Tecnico.

Pirotti, F., Guarnieri, A., Vettore, A. 2013a. State of the art of ground and aerial laser scanning technologies for highresolution topography of the earth surface. European Journal of Remote Sensing, 46, pp. 66-78.

Pirotti, F., Guarnieri, A., Vettore, A., 2013b. Vegetation filtering of waveform terrestrial laser scanner data for DTM production. Applied Geomatics, 5(4), pp. 311-322.

Regione Toscana, Servizio Geografico Regionale, 2007. Appalto per la prestazione del servizio di realizzazione prodotti ripresa LiDAR e fotogrammetria: capitolato speciale. 
The International Archives of the Photogrammetry, Remote Sensing and Spatial Information Sciences, Volume XL-5/W3, 2013 The Role of Geomatics in Hydrogeological Risk, 27 - 28 February 2013, Padua, Italy

Surace, L., 1998. La georeferenziazione delle informazioni territoriali, Bollettino di Geodesia e Scienze Affini 57-2, pp. 181-234. 